\title{
Parasitology
}

http://journals.cambridge.org/PAR

Additional services for Parasitology:

Email alerts: $\underline{\text { Click here }}$

Subscriptions: $\underline{\text { Click here }}$

Commercial reprints: Click here

Terms of use : $\underline{\text { Click here }}$

\section{Development and application of a delayed-release anthelmintic intra- ruminal bolus system for experimental manipulation of nematode worm burdens}

\section{ANJA M. CARLSSON, KENNETH WILSON and R. JUSTIN IRVINE}

Parasitology / Volume 139 / Issue 08 / July 2012, pp 1086 - 1092

DOI: 10.1017/S0031182012000406, Published online: 15 March 2012

Link to this article: http://journals.cambridge.org/abstract_S0031182012000406

How to cite this article:

ANJA M. CARLSSON, KENNETH WILSON and R. JUSTIN IRVINE (2012). Development and application of a delayedrelease anthelmintic intra-ruminal bolus system for experimental manipulation of nematode worm burdens. Parasitology, 139, pp 1086-1092 doi:10.1017/S0031182012000406

Request Permissions : $\underline{\text { Click here }}$ 


\title{
Development and application of a delayed-release anthelmintic intra-ruminal bolus system for experimental manipulation of nematode worm burdens
}

\author{
ANJA M. CARLSSON ${ }^{1,2,3 *}$, KENNETH WILSON ${ }^{1}$ and R. JUSTIN IRVINE ${ }^{2}$ \\ ${ }^{1}$ Lancaster Environment Centre, Lancaster University, Lancaster LA1 4YQ, UK \\ ${ }^{2}$ The Fames Hutton Institute, Craigiebuckler, Aberdeen AB15 8QH, UK \\ ${ }^{3}$ Department of Arctic Biology, University Centre in Svalbard, PO Box 156, NO-9171 Longyearbyen, Norway
}

(Received 7 December 2011; revised 9 February 2012; accepted 12 February 2012; first published online 15 March 2012)

SUMMARY

In order to quantify the impact of parasites on host population dynamics, experimental manipulations that perturb the parasite-host relationship are needed but, logistically, this is difficult for wild hosts. Here, we describe the use of a delayedrelease anthelmintic delivery system that can be administered when the hosts can be captured and its activity delayed until a more appropriate period in the host-parasite cycle. Our model system is Svalbard reindeer infected with a nematode parasite, Marshallagia marshalli, which appears to accumulate during the Arctic winter. To determine the extent to which this occurs and the effect on host fitness, reindeer need to be treated with anthelmintics in late autumn but they can only be caught and handled in April. To solve this problem, we devised an intra-ruminal capsule that releases the anthelmintic from up to 6 months after being administered. The capsule was trialed in cannulated sheep and red deer to determine optimum capsule orifice size and release rates. Capsules were estimated to release placebo for 100-153 days followed by abamectin for 22-34 days. To test the efficacy of treatment in reindeer, capsules were administered in April and retrieved in October. All capsules had fully released the anthelmintic and treated reindeer had significantly lower worm burdens than controls. Thus, success of this system allows repeated treatment over several years to test the effect of winter parasitism on host fitness.

Key words: anthelmintic experiment, nematode, ruminant, parasite-host interaction.

\section{INTRODUCTION}

Theoretical studies have shown that parasites have the potential to regulate host abundance through effects on reproduction and survival of the host (Anderson and May, 1978; May and Anderson, 1978). In spite of the increasing recognition of the importance of parasites in population ecology and wildlife conservation, knowledge of host-parasite interactions in the wild remains limited (Smith et al. 2009). In domesticated livestock it is well recognized that gastrointestinal nematodes cause significant disease through negative effects on growth and survival of the host, resulting in major economic losses (Perry and Randolph, 1999). Consequently, the ecology of parasites in agricultural systems has been studied in detail in order to understand how best to control and limit disease (Alison, 2003; O'Connor et al. 2006). Traditionally, the study of parasites in wild animals has relied on making assumptions based on domesticated animals. However, the epidemiology of host-parasite dynamics in the wild is often very different. At best, cross-sectional studies of carcasses and fecal egg counts can be carried out (Morgan et al.

\footnotetext{
* Corresponding author: Lancaster Environment Centre, Lancaster University, Lancaster LA1 4YQ, UK. Tel: 01524 93406. E-mail: a.carlsson@lancs.ac.uk
}

2005; Newey et al. 2005; Irvine et al. 2006); however, the consequences of parasitism are difficult to determine through these types of studies (Gulland, 1995; Stien et al. 2002; Wilson et al. 2002). To investigate the effects of parasitism on the host, experiments that perturb the host-parasite relationship are essential (Stien et al. 2002). One of the major constraints in conducting such experiments is the logistical difficulties associated with accessing, treating and handling wild animals.

Experimental perturbations of the parasite communities in wild animals generally rely on the use of anthelmintics to reduce parasite burdens (Murray et al. 1996; Irvine, 2000; Craig et al. 2009). However, the ability to reduce worm burdens experimentally is limited to the time when anthelmintics can be administered and the duration of the effective treatment period. Usually, a single oral dosing or injection is used to deliver the anthelmintic in the wild (Murray et al. 1997; Hudson et al. 1998; Irvine, 2000; Newey et al. 2005; Pedersen and Greives, 2008) and the period of efficacy is generally a maximum of 3-5 weeks. However, slow-release intra-ruminal devices have been developed for livestock which deliver a therapeutic dose over a period of up to 100 days (Cardinal, 1997; Vandamme and Ellis, 2004) reducing both labour and material costs in the control of nematode parasites. These devices have advantages 
for wildlife research, allowing a single treatment to provide a lengthy parasite-free period in animals that are difficult to catch or can be caught only at specific times of the year.

The application of slow-release capsules has been successfully utilized on Soay sheep (Gulland et al. 1993) and Svalbard reindeer (Rangifer tarandus platyrhynchus) (Stien et al. 2002). In the latter case, these capsules were administered to reindeer in April, which reduced worm burdens for approximately 3 months and confirmed that Ostertagia gruehneri transmission occurs in spring (Albon et al. 2002). Furthermore, treatment also demonstrated that there was a parasite-mediated reduction in host fecundity that was sufficient to regulate the population dynamics of Svalbard reindeer (Albon et al. 2002). However, cross-sectional studies have also indicated that the other major nematode species of Svalbard reindeer (Marshallagia marshalli) is almost absent during the summer but increases during winter, suggesting over-winter transmission, but the consequence of this infection on reindeer performance has not yet been quantified (Irvine et al. 2000). To determine the transmission dynamics of $M$. marshalli, and the impact of the parasite on the fecundity and survival of the host, an experiment is needed in which reindeer are treated at the start of the winter. However, logistical and environmental constraints make it impossible to catch and treat animals at this time of year.

In this study, we describe the adaptation and application of a delayed-release anthelminitic delivery system. Domestic sheep and farmed red deer (Cervus elaphus) were used as model systems, and the efficacy was tested against the abomasal nematodes of Svalbard reindeer. The aim was to develop a device that can be administered in April when Svalbard reindeer can be most easily caught, but to delay delivery of the anthelmintic until autumn several months later. This would then allow quantification of the effect of winter parasitism on host fitness parameters in a later study. We predicted that Svalbard reindeer treated with the delayed-release bolus would have significantly lower worm burdens in October compared to controls.

\section{MATERIALS AND METHODS}

\section{Capsule design}

Capsules used in this study were small slow-release intra-ruminal capsules (Argenta Manufacturing Limited, NZ) that comprise a plastic hollow cylinder capped at both ends containing up to 11 tablets (identical in size and mode of action to the capsules used by Stien et al. (2002)). One end is closed and includes a spring that pushes the tablets towards the orifice in the opposite end. The orifice allows rumen fluid to enter the capsule and sequentially dissolves the tablets within the cylinder; the resulting gel is pushed out of the capsule at a rate determined by the size of the orifice. Retention of the capsule in the rumen is achieved by polymeric wings attached to the cylinder. During administration, the wings are constrained to the cylinder with water-soluble tape, subsequently the tape dissolves and the wings open, preventing regurgitation of the device. Each capsule was fitted with a unique identifying number to ensure traceability and linking the capsule to batch number, formulation code, orifice size, spring strength, plunger type, capsule type and date of manufacture. All capsules were administered orally using a capsule applicator gun.

\section{Rumen-cannulated sheep}

The trial was carried out using 3 rumen-cannulated sheep held at the Macaulay Land Use Research Institute's Glensaugh research farm, Aberdeenshire, Scotland $\left(56.8^{\circ} \mathrm{N}, 2.6^{\circ} \mathrm{E}\right)$, in July 2005 . The duration of release from slow-release capsules fitted with orifices of $4 \cdot 0,3 \cdot 7$ and $3 \cdot 5 \mathrm{~mm}$ diameter and thickness of $2 \mathrm{~mm}$ was determined. Each capsule contained 9 tablets of placebo (35\% hydrated aluminium silicate) followed by 2 tablets containing $3 \cdot 2 \%$ abamectin. Each sheep was fitted with 2 capsules of each size (total of 6 capsules per sheep). The capsules were attached to silicon tubing using cable ties and tethered to the cannula bung. The capsules were retrieved from the sheep rumens on days $0,24,50,78$ and 106 and the core length of each capsule was measured using vernier calipers from the lower edge of the plunger (coloured red to aid visibility) to the inner edge of the orifice plate. Not all capsules were recovered at all sampling dates, as some were lost when they became detached from the silicon tubing that tethered them to the cannula bung.

Release rates, defined as the reduction in tablet size (mm per day since capsule administration), were calculated from the core-length measurements using linear mixed effect models from the lme package in $\mathrm{R}$ version 2.13.0 (R Development Core Team, 2011), with sheep identity and capsule as random effects, and days since initiation of experiment and orifice size as fixed effects. Model fit was assessed using diagnostic plots of fitted values and residuals. Logtransforming the response variable improved model fit and linearized the data. However, estimates from this model were unrealistic, predicting periods of release on a log-scale ( $>460$ days) well in excess of those observed (e.g. we know that capsules from reindeer culled 6 months after treatments were fully discharged).

\section{Red deer}

From trials in sheep it was determined that the smallest orifice size was the most appropriate design 
and the release rate of capsules was tested in red deer. The trial was carried out using red deer at the Glensaugh research farm (see above). Six yearling red deer were each given 1 capsule with 11 placebo (35\% hydrated aluminum silicate) tablets and orifice diameter of $3.5 \mathrm{~mm}$ and thickness of $2 \mathrm{~mm}$ on days 0,36 , and 63 of the experiment. The animals were kept under normal management until they were slaughtered on day 100 of the experiment and all capsules recovered from the rumen. At the end of the experiment, the core-length of each capsule was measured as described above. All capsules were successfully retrieved and identified by the end of the trial. Release rate, as defined above, was predicted using linear mixed effect models using the lme package in $\mathrm{R}$ version 2.13.0 ( $\mathrm{R}$ Development Core Team, 2011) with deer identity as a random effect and days since capsule administration until cull as a fixed effect.

\section{Svalbard reindeer}

Svalbard reindeer are a wild population living on the high Arctic archipelago of Svalbard (Halvorsen and Bye, 1999). Female Svalbard reindeer have been marked and caught annually in the ColesdalenReindalen valley system, Nordenskiöldland, Spitsbergen $\left(77^{\circ} 50-78^{\circ} 20 \mathrm{~N}, 1^{\circ} 00-17^{\circ} 30 \mathrm{E}\right)$ since 1994, allowing treatment and recapture of known individuals (Milner et al. 2003). Between 11-26 April 2006 and 2007, 62 adult female reindeer (36 months or older) were randomly allocated for treatment and fitted with an intra-ruminal controlled-release capsule with an orifice diameter of $3.5 \mathrm{~mm}$ and thickness of $2 \mathrm{~mm}$. Each capsule contained 9 tablets of placebo and 2 tablets abamectin, in order to delay treatment until autumn. In 2006 the concentration of abamectin in tablets was $3 \cdot 2 \%$. In their original design, the estimated dose rate with abamectin of this concentration was $23 \mu \mathrm{g} / \mathrm{kg} /$ day; however, these figures were based on sheep weighing $80 \mathrm{~kg}$, using capsules with orifice diameter of $4.5 \mathrm{~mm}$. The orifice diameter of the reindeer capsules was smaller, and it is therefore likely that the abamectin dose rate was lower. The following year the abamectin dose was doubled (to $6 \%$ ) to compensate for the smaller orifice size in the delayed release capsules, with estimated delivery rate of $45 \mu \mathrm{g} / \mathrm{kg} /$ day. Administration of capsules was performed as outlined above. To assess the efficacy of the treatment, 16 control and 4 treated animals were culled in late October 2006 and 2007 and the abomasums recovered 186-194 days after administration. Stien et al. (2002) have previously reported on an experiment where animals were treated with immediate-acting anthelmintic drugs in April, using ivermectin capsules (Ivomec Maximizer, Merial Animal Health Ltd, Harlow Essex, UK) and/or injectable moxidectin, to reduce worm burdens in Svalbard reindeer during the summer. To demonstrate the difference in efficacy between the immediate, and delayed anthelmintic drug treatment in removing nematode burdens in October, a subset of these data was analysed. Abundance data of $M$. marshalli and O. gruheneri adult worms from 7 Svalbard reindeer treated with immediate-acting anthelmintics and 10 non-treated Svalbard reindeer culled October 1999 were used. For more details of these experiments see the report by Stein et al. (2002). Abomasums were removed from culled reindeer and adult nematodes were extracted and counted as described by Halvorsen et al. (1999) and Irvine et al. (2000). A subset of adult male nematodes was identified to species using morphology (Drozdz, 1965), with minor and major morphs grouped according to recent molecular findings (Dallas et al. 2000, 2001). Adult nematode abundance for each species was estimated using the proportion of identified worms and scaling up to the population level based on the worm counts. The effect of the 3 different treatments (control, immediate-acting anthelmintic and delayed-release anthelmintic capsule) on adult nematode worm burden was analysed using generalized linear models with a $\log \operatorname{link}$ function, assuming the nematode counts came from a negative binomial distribution (Wilson et al. 1996). For animals treated with delayed-release capsule, a separate analysis was run to check for differences in treatment efficacy between the 2 treatment years (2006 and 2007). Data were analysed using the glm. $\mathrm{nb}$ function from the MASS package in $\mathrm{R}$ version 2.13.0 (R Development Core Team, 2011).

\section{Animal ethics}

All procedures on red deer and sheep were carried out by R. J. Irvine, who has a personal license (PIL 60/ 11369) issued by the UK Government Home Office under the Scientific Procedures on Living Animals Regulations (Animals (Scientific Procedures) Act 1986). All capture and live-animal procedures on Svalbard were performed under license from the Norwegian National Animal Research Authority with a veterinary surgeon in attendance.

\section{RESULTS}

\section{Rumen-cannulated sheep}

As expected, the core length in all capsules decreased significantly over time $\left(\mathrm{F}_{1,56}=1305, P<0 \cdot 001\right)$, and the rate of decrease varied significantly with orifice size $\left(\mathrm{F}_{2,56}=7 \cdot 56, P=0 \cdot 0012\right)$ (Fig. 1). The core length of capsules with orifice diameter of $4.0 \mathrm{~mm}$ declined the fastest $\left(\mathrm{t}_{2,56}=3 \cdot 5, P<0 \cdot 001\right)$, with an estimated mean release rate of $0.46( \pm 0.03) \mathrm{mm}$ per day. There was no significant difference in core length decline rate in capsules with an orifice diameter of 3.5 and $3.7 \mathrm{~mm}\left(\mathrm{t}_{1,56}=0.29, P=0.76\right)$, which had estimated rates of release of $0 \cdot 35( \pm 0 \cdot 02)$ and $0 \cdot 36( \pm 0 \cdot 03) \mathrm{mm}$ 


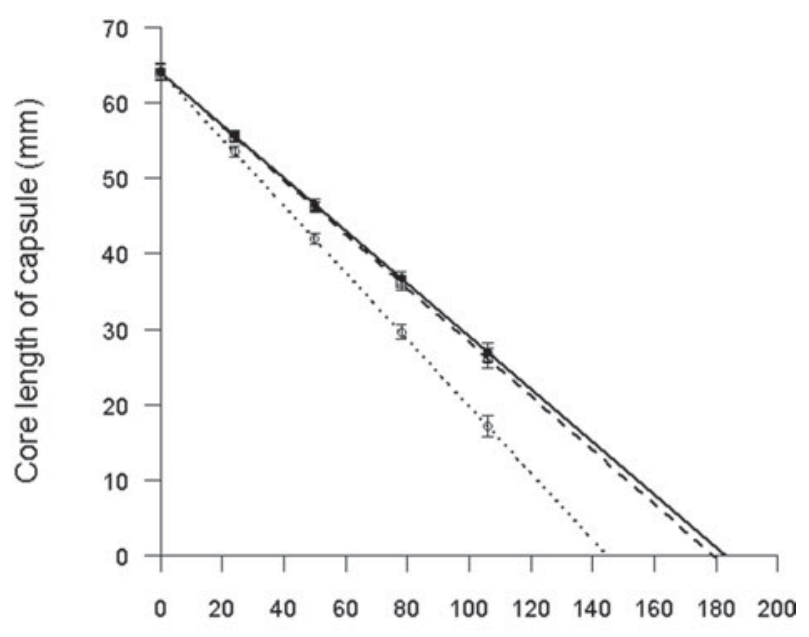

\section{Days since administration}

Fig. 1. Estimated rate of decline of the core length of intra-ruminal capsules with an orifice diameter of $3 \cdot 5$ (solid lines), $3 \cdot 7$ (dashed lines) and $4 \cdot 0$ (dotted lines) $\mathrm{mm}$ in rumen-cannulated sheep. Symbols indicate means \pm standard errors from the minimal model, standardized for 1 animal.

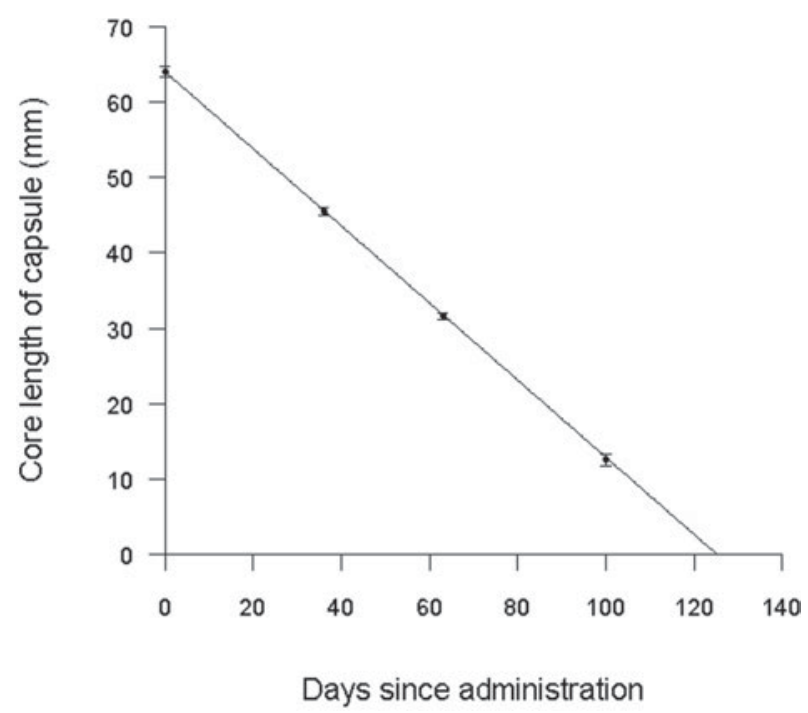

Fig. 2. Estimated rate of decline of the core length of intra-ruminal capsules with an orifice diameter of $3.5 \mathrm{~mm}$ in red deer. Symbols indicate means \pm standard errors as predicted from the minimal model, standardized for 1 animal.

per day, respectively. Based on the tablet release rate of the capsule with the smallest orifice size, all tablets were predicted to be released in $183( \pm 9)$ days, with 1 tablet being dissolved approximately every 17 th day after administration (Fig. 1). There was no evidence of clogging or blockage of the orifice in any of the capsules.

\section{Red deer}

The core length in all capsules decreased significantly over time $\left(\mathrm{F}_{1,17}=1825, P<0 \cdot 001\right)$; the estimated

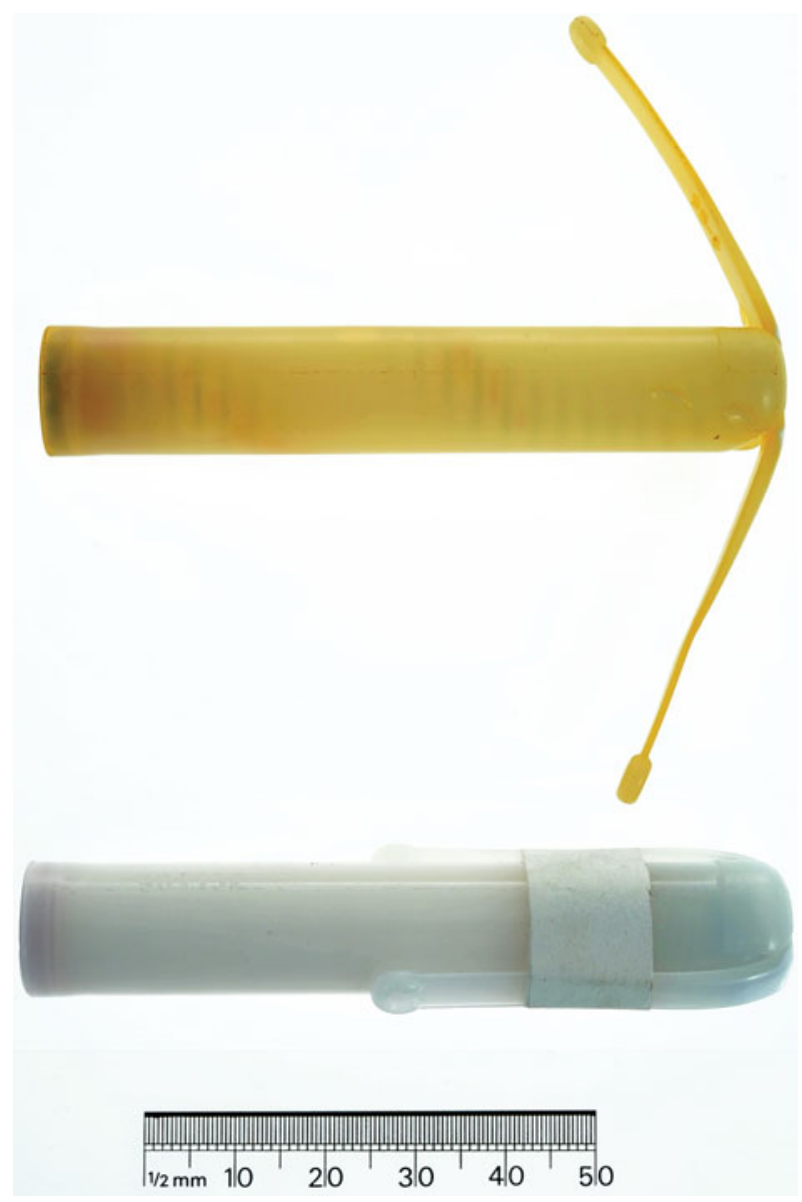

Fig. 3. Photo of the delayed-release intra-ruminal bolus before administration (bottom) and after recovery from the rumen following successful release of all anthelmintic tablets (top).

release rate of capsules with orifice diameter of $3.5 \mathrm{~mm}$ was $0.51( \pm 0.01) \mathrm{mm}$ per day. In deer, the estimated time until all tablets were released was therefore 125 ( \pm 2 ) days (Fig. 2), with 1 tablet being dissolved every 11 th day. None of the administered capsules were blocked or clogged upon retrieval.

\section{Svalbard reindeer}

Since the sheep and deer trials suggested the delayedrelease capsules lasted for between 4 and 6 months, reindeer were culled 186-194 days after capsule administration. All capsules recovered from treated reindeer had successfully released all tablets. A photo of a capsule before administration and after recovery from the rumen following successful release of tablets can be seen in Fig. 3. Counts of O. gruehneri adult worms of Svalbard reindeer culled in October showed that treated animals overall had lower worm burdens than controls $\left(\chi_{2,35}^{2}=45 \cdot 48, P<0 \cdot 001\right)$, but that those treated with delayed-release anthelmintic capsule also had significantly lower O. gruheneri burdens than those animals treated with immediateacting anthelmintics $\left(z_{2,35}=-4 \cdot 235, \quad P<0 \cdot 001\right.$; Fig. 4a). For O. gruehneri there was also a 
(a)

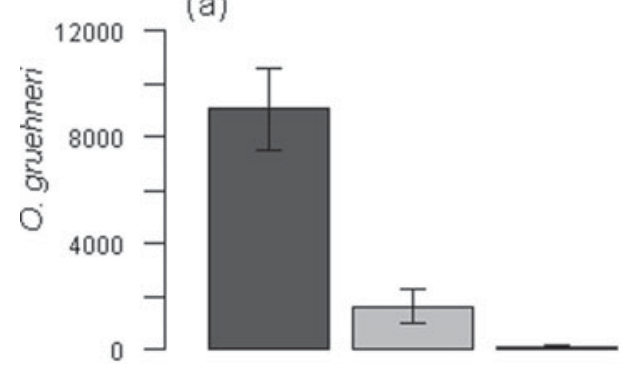

(b)

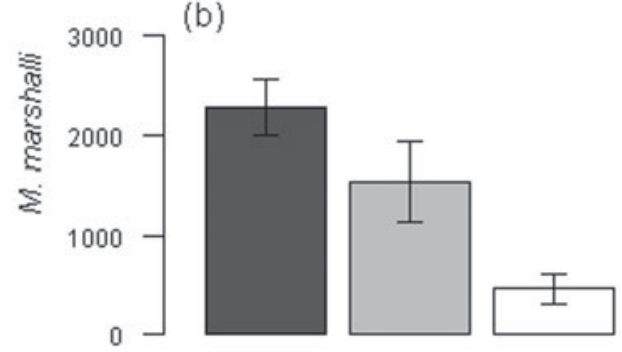

Fig. 4. Estimated mean ( \pm standard error) adult worm burdens/animal across all sampling years of (a) Ostertagia gruehneri and (b) Marshallagia marshalli for Svalbard reindeer culled in October as predicted by best fit model. Non-treated, control (dark grey bars), treated with immediate-acting anthelmintics (light grey bars after Stien et al. 2002), and treated with delayed-release anthelmintic capsule (open bars).

between-year difference $\left(\chi_{1,18}^{2}=51 \cdot 2, \quad P<0 \cdot 001\right)$, where the effect of the delayed treatment was stronger and worm burdens significantly lower in animals treated in 2007, when the abamectin dose rate was higher, compared with those treated in 2006. For $M$. marshalli only the delayed-release anthelmintic capsule successfully reduced worm burdens in October $\left(z_{2,35}=-4 \cdot 585, P<0 \cdot 001\right)$, there being no significant difference in $M$. marshalli burdens between the non-treated control animals and animals treated with immediate-acting anthelmintic capsule $\left(z_{2,35}=-1 \cdot 349, P=0 \cdot 177 ;\right.$ Fig. $\left.4 b\right)$. There was no difference in treatment effect of the delayed-release anthelmintic capsule between years for $M$. marshalli burdens $\left(\chi_{1,16}^{2}=1 \cdot 768, P=0 \cdot 18\right)$.

\section{DISCUSSION}

This study demonstrates that, through the modification of the intra-ruminal capsule design, and the use of a combination of placebo and therapeutic tablets, we were able to delay delivery of anthelmintics to individuals in a wild animal population. This novel method allows us to experimentally manipulate parasite burdens at a time of year when it is impossible to treat animals by any other method. Thus, we have developed a mechanism that will allow us to test the magnitude and effect of over-winter transmission of parasites during the harsh Arctic winter when hosts are already under severe nutritional stress.

To overcome logistical and management constraints associated with working with free-ranging wild animals, we used sheep and deer models to determine optimal capsule design. For intra-ruminal devices where drug delivery is based on diffusion, the rate of release is governed by the size of the orifice: if the orifice is too small it can lead to build-up of tablet residue, which will block the orifice and prevent the remaining anthelmintic from being released. Therefore, release rates from capsules fitted with different size orifices were first established in sheep with the aim of determining the smallest size orifice with release rates that would allow administration of the bolus up to 6 months prior to the drug being released. Release rates of the capsule with the $3.5 \mathrm{~mm}$ orifice size were then trialed in red deer. Release rates were faster in deer, with an estimated 125 days until all tablets were dissolved compared to 183 days in sheep. This variation could, in part, be due to the difference in methodology between the two trials. Whilst the deer had an intact rumen, the sheep were fitted with an intra-ruminal cannula in order to allow repeated measurements of the same capsule. Tethering the capsule to the bung changes normal capsule movement in the rumen, and each time the cannula is removed the rumen environment is disturbed, which could have an effect on the release rate of the tablets (Vandamme and Ellis, 2004). But the difference in release rates could also be due to biological differences in the rumen environment and microflora between cervids and bovids affecting the function of the capsule. Further, the capsules fitted in the sheep contained 2 tablets of abamectin, whilst those administered to deer contained only placebo tablets. The difference in chemical composition of these tablets may also affect the rate at which they are dissolved (Cardinal, 1997; Vandamme and Ellis, 2004).

Since Svalbard reindeer are wild, free-ranging animals, detailed studies of anthelmintic release rates could not be conducted in the field because it is not possible to cull treated individuals sequentially over the release period. However, by culling animals in October, approximately 6 months after administration of the delayed-release anthelmintic capsule, we were able to demonstrate that all tablets had successfully dissolved, and that animals treated with the delayed anthelmintic bolus had significantly lower burdens of adult nematodes of both major species compared to controls. Animals treated with the delayed bolus still harboured abomasal nematodes but at much lower levels compared to controls and those treated with immediate-acting anthelmintics. The presence of low numbers of adult nematodes in the treated animals could be because the release rate was similar to that found in red deer (125 days), in which case the anthelmintic would have been 
delivered mid-August, allowing time for reindeer to become re-infected by ingesting infective larvae from the pasture. Although there is increasing evidence of resistance to a range of anti-parasitic agents in nematodes of domestic livestock, it is unlikely that nematodes of Svalbard reindeer have significant anthelmintic resistance. The anthelmintic used in this trial is of the macrocyclic lactone, avermectin class, which has good potency and broad spectrum activity against nematodes and acarines (Shoop et al. 1995; McKellar and Jackson, 2004). Anthelmintics of the avermectin class have been shown to be effective and safe for treatment against nematodes for a range of adult domesticated wild ruminants (Marley and Conder, 2002) as well as some wild freeranging populations (Irvine, 2000; Craig et al. 2009). Alternatively, the presence of low levels of adult nematodes in the treated animals could reflect that the dose rate of abamectin was suboptimal in capsules with orifice diameter of $3.5 \mathrm{~mm}$, but this issue could be addressed by increasing the concentration of abamectin to improve the therapeutic dose. In fact, burdens of $O$. gruehneri in treated animals were lower in 2007 (285 vs 651) when the dose rate of abamectin was increased. Nonetheless, the abundance of adult nematodes of both major species was significantly reduced in both treatment years. Although the efficacy of anthelmintics in removing nematode burdens of Svalbard reindeer in the summer has previously been demonstrated (Stien et al. 2002), only the delayed-release anthelmintic capsule successfully reduced $M$. marshalli burdens in the winter (Fig. 4b). Consequently, experimental treatments with delayed-release capsules offer potential insights into both the over-winter transmission dynamics of the gastrointestinal nematodes of Svalbard reindeer and their impact on host fitness.

Intra-ruminal devices revolutionized drug delivery in agricultural systems and, as illustrated here, can be a useful tool for studying parasite-host interactions of wild ruminants. By modifying a readily available commercial system, the logistical constraints associated with studying a free-ranging ruminant in the Arctic have been overcome. There are a range of intra-ruminal devices of different designs and modes of action in use for the delivery of growth promoters, nutrients and anti-parasitic drugs, all of which could potentially be utilized in studies of wild ruminant population ecology (Vandamme and Ellis, 2004). Controlled release devices have for example been used to estimate forage intake in mule deer (Kuzyk and Hudson, 2006) and to establish the effect of trace elements on the population dynamics of black-tailed deer (Flueck, 1994). Although intra-ruminal devices are now routinely used in livestock it is vital to ascertain that the device, delivery time and dose rate chosen is safe for the species in question, as inappropriate designs could have adverse effects when administered.

\section{ACKNOWLEDGMENTS}

We thank Sysselmannen (Governor of Svalbard), Svalbard for permission to carry out fieldwork. Mitch Venning of Nufarm Health and Sciences, New Zealand for advice on development and production of the boluses, and Odd Halvorsen at the University of Oslo for parasite identification. We are grateful to the field teams for capturing the reindeer, especially Steve Albon, Leif Egil Loe, Erik Ropstad, Audun Stien and Vebjorn Veiberg. This work was funded by the Macaulay Development Trust and a NERC-CASE Studentship (NE/F01354X/1) awarded to Kenneth Wilson, Steve Albon, Justin Irvine and Stephen J. Coulson.

\section{REFERENCES}

Albon, S. D., Stien, A., Irvine, R. J., Langvatn, R., Ropstad, E. and Halvorsen, O. (2002). The role of parasites in the dynamics of a reindeer population. Proceedings of the Royal Society of London, B 269, 1625-1632. doi: DOI: $10.1098 / \mathrm{rspb} .2002 .2064$.

Alison, P. G. (2003). Immunity, antigenic heterogeneity, and aggregation of helminth parasites. The Fournal of Parasitology 89, 232-241.

Anderson, R. and May, R. (1978). Regulation and stability of host-parasite population interaction. I. Regulatory processess Fournal of Animal Ecology 47, 219-247

Cardinal, J. R. (1997). Intraruminal devices. Advanced Drug Delivery Reviews 28, 303-322.

Craig, B. H., Jones, O.R., Pilkington, J. G. and Pemberton, J.M. (2009). Re-establishment of nematode infra-community and host survivorship in wild Soay sheep following anthelmintic treatment. Veterinary Parasitology 161, 47-52. doi: 10.1016/j.vetpar.2008.11.027.

Dallas, J. F., Irvine, R. J. and Halvorsen, O. (2000). DNA evidence that Ostertagia gruehneri and Ostertagia arctica (Nematoda: Ostertagiinae) in reindeer from Norway and Svalbard are conspecific. International fournal for Parasitology 30, 655-658.

Dallas, J. F., Irvine, R. J. and Halvorsen, O. (2001). DNA evidence that Marshallagia marshalli Ransom, 1907 and M-occidentalis Ransom, 1907 (Nematoda: Ostertagiinae) from Svalbard reindeer are conspecific. Systematic Parasitology 50, 101-103.

Drozdz, J. (1965). Studies on helminths and helminthiases in Cervidae. I. Revision of the subfamily Ostertagiinae Sarwar, 1965 and an attempt to explain the phylogenesis of its representatives. Acta Parasitologica Polonica, 13, 445-481.

Flueck, W. T. (1994). Effect of trace-elements on population-dynamicsselinium deficiency in free-ranging black-tailed deer. Ecology 75, 807-812.

Gulland, F. M. D. (1995). The Impact of Infectious Diseases on Wild Animal Populations - A Review. Cambridge University Press, Cambridge, UK.

Gulland, F. M. D., Albon, S. D., Pemberton, J. M., Moorcroft, P. R. and Cluttonbrock, T.H. (1993). Parasite-associated polymorphism in a cyclic ungulate population. Proceedings of the Royal Society of London, B 254, 7-13.

Halvorsen, O. and Bye, K. (1999). Parasites, biodiversity, and population dynamics in an ecosystem in the High Arctic. Veterinary Parasitology 84, 205-227.

Hudson, P. J., Dobson, A. and Newborn, D. (1998). Prevention of population cycles by parasite removal. Science 282, 2256-2258.

Irvine, R. J. (2000). Use of moxidectin treatment in the investigation of abomasal nematodiasis in wild reindeer (Rangifer tarandus platyrhynchus). Veterinary Record 147, 570-573.

Irvine, R. J., Corbishley, H., Pilkington, J. G. and Albon, S. D. (2006). Low-level parasitic worm burdens may reduce body condition in freeranging red deer (Cervus elaphus). Parasitology 133, 465-475. doi: 10.1017/ s0031182006000606.

Irvine, R. J., Stien, A., Halvorsen, O., Langvatn, R. and Albon, S. D. (2000). Life-history strategies and population dynamics of abomasal nematodes in Svalbard reindeer (Rangifer tarandus platyrhynchus). Parasitology 120, 297-311.

Kuzyk, G. W. and Hudson, R. J. (2006). Using n-alkane markers to estimate forage intake of mule deer. Canadian Fournal of Zoology-Revue Canadienne de Zoologie 84, 1576-1583. doi: 10.1139/z06-156.

Marley, S. E. and Conder, G. A. (2002). The Use of Macrocyclic Lactones to Control Parasites of Domesticates Wild Ruminants. In Macrocyclic Lactones in Antiparasitic Therapy (ed. Vercruysse, I. and Rew, R. S.), pp. 371-394. CABI International, Wallingford, UK. 
May, R. and Anderson, R. (1978). Regulation and stability of host-parasite population interaction. II. Destabalizing processes. Fournal of Animal Ecology 47, 249-267.

McKellar, Q. A. and Jackson, F. (2004). Veterinary anthelmintics: old and new. Trends in Parasitology 20, 456-461. doi: 10.1016/j, pt.2004.08.002.

Milner, J. M., Stien, A., Irvine, R. J., Albon, S. D., Langvatn, R. and Ropstad, E. (2003). Body condition in Svalbard reindeer and the use of blood parameters as indicators of condition and fitness. Canadian Fournal of Zoology-Revue Canadienne de Zoologie 81, 1566-1578

Morgan, E. R., Shaikenov, B., Torgerson, P. R., Medley, G. F. and Milner-Gulland, E. J. (2005). Helminths of saiga antelope in Kazakhstan: Implications for conservation and livestock production. Fournal of Wildlife Diseases 41, 149-162.

Murray, D. L., Cary, J. R. and Keith, L. B. (1997). Interactive effects of subleathal nematodes and nutritional status on Snowshoe hare vulnerability to predation. The Fournal of Animal Ecology 66, 250-264.

Murray, D. L., Keith, L.B. and Cary, J. R. (1996). The efficacy of anthelmintic treatment on the parasite abundance of free ranging snowshoe hares. Canadian Fournal of Zoology-Revue Canadienne de Zoologie 74, 1604-1611.

Newey, S., Shaw, D. J., Kirby, A., Montieth, P., Hudson, P. J. and Thirgood, S. J. (2005). Prevalence, intensity and aggregation of intestinal parasites in mountain hares and their potential impact on population dynamics. International fournal for Parasitology 35 $367-373$.

O'Connor, L. J., Walkden-Brown, S. W. and Kahn, L. P. (2006). Ecology of the free-living stages of major trichostorngylid parasites of sheep. Veterinary Parasitology 14, 1-15.
Pedersen, A. B. and Greives, T. J. (2008). The interaction of parasites and resources cause crashes in a wild mouse population. Fournal of Animal Ecology 77, 370-377.

Perry, B. D. and Randolph, T. F. (1999). Improving the assessment of the economic impact of parasitic diseases and of their control in production animals. Veterinary Parasitology 84, 145-168.

R Development Core Team. (2011). R: A language and environment for statistical computing. Vienna, Austria. URL http://www.R-project.org Shoop, W. L., Mrozik, H. and Fisher, M.H. (1995). Structure and activity of avermectins and milbemycins in animal health. Veterinary Parasitology 59, 139-156.

Smith, K. F., Acevedo-Whitehouse, K. and Pedersen, A. B. (2009) The role of infectious diseases in biological conservation. Animal Conservation 12, 1-12. doi: 10.1111/j.1469-1795.2008.00228.x.

Stien, A., Irvine, R. J., Ropstad, E., Halvorsen, O., Langvatn, R. and Albon, S. D. (2002). The impact of gastrointestinal nematodes on wild reindeer: experimental and cross-sectional studies. Fournal of Animal Ecology 71, 937-945.

Vandamme, T.F. and Ellis, K. J. (2004). Issues and challenges in developing ruminal drug delivery systems. Advanced Drug Delivery Reviews 56, 1415-1436. doi: 10.1016/j.addr.2004.02.011.

Wilson, K., Bjørnstad, O. N., Dobson, A. P., Merler, S., Poglayen, G., Randolph, S. E., Read, A. F. and Skorping, A. (2002). Heterogeneities in macroparasite infections: patterns and processes. In The Ecology of Wildlife Diseases (ed. Hudson, P. J., Rizzoli, A., Grenfell, B. T., Heesterbeek, J. A. P. and Dobson, A. P.), pp. 6-44. Oxford University Press, Oxford, UK.

Wilson, K., Grenfell, B. T. and Shaw, D. J. (1996). Analysis of aggregated parasite distributions: a comparison of methods. Functional Ecology 10 592-601. 